\title{
Influence of Biopsy Technique on Molecular Genetic Tumor Characterization in Non-Small Cell Lung Cancer-The Prospective, Randomized, Single-Blinded, Multicenter PROFILER Study Protocol
}

\author{
Maik Haentschel ${ }^{1, *}$, Michael Boeckeler ${ }^{1}$, Irina Bonzheim ${ }^{2}$, Florian Schimmele ${ }^{3}$, \\ Werner Spengler ${ }^{1}$, Franz Stanzel ${ }^{4}$, Christoph Petermann ${ }^{5}$, Kaid Darwiche ${ }^{6} \mathbb{D}$, Lars Hagmeyer ${ }^{7}$, \\ Reinhard Buettner ${ }^{8}$, Markus Tiemann ${ }^{9}$, Hans-Ulrich Schildhaus ${ }^{10}{ }^{\circ}$, Rainer Muche ${ }^{11}$, \\ Hans Boesmueller ${ }^{2}{ }^{\circledR}$, Felix Everinghoff ${ }^{1}$, Robert Mueller ${ }^{1}$, Bijoy Atique ${ }^{1}$, \\ Richard A. Lewis ${ }^{12}{ }^{-}$, Lars Zender ${ }^{1}$, Falko Fend ${ }^{2}$ and Juergen Hetzel ${ }^{1,13}$ \\ 1 Department of Medical Oncology and Pneumology, Eberhard Karls University, 72076 Tübingen, Germany; \\ Michael.boeckeler@med.uni-tuebingen.de (M.B.); werner.spengler@med.uni-tuebingen.de (W.S.); \\ felix.everinghoff@gmx.de (F.E.); Robert.mueller@med.uni-tuebingen.de (R.M.); \\ Naushad-Bijoy.atique@med.uni-tuebingen.de (B.A.); Lars.Zender@med.uni-tuebingen.de (L.Z.); \\ Juergen.hetzel@med.uni-tuebingen.de (J.H.) \\ 2 Institute of Pathology and Neuropathology, Reference Center for Haematopathology University Hospital, \\ Tuebingen Eberhard-Karls-University, 72076 Tübingen, Germany; \\ Irina.Bonzheim@med.uni-tuebingen.de (I.B.); hans.boesmueller@med.uni-tuebingen.de (H.B.); \\ Falko.Fend@med.uni-tuebingen.de (F.F.) \\ 3 Department of Internal Medicine, Gastroenterology and Tumor Medicine, Paracelsus Hospital, \\ 73760 Ostfildern-Ruit, Germany; f.schimmele@medius-kliniken.de \\ 4 Center for Pneumology, 58675 Hemer, Germany; franz.stanzel@lkhemer.de \\ 5 Department for Pulmonary Diseases, Asklepios-Klinik Harburg, 21075 Hamburg, Germany; \\ c.petermann@asklepios.com \\ 6 Department of Interventional Pneumology, Ruhrlandklinik, University Hospital Essen, \\ University of Duisburg-Essen, 45239 Essen, Germany; kaid.darwiche@rlk.uk-essen.de \\ 7 Clinic for Pneumology and Allergology, Center of Sleep Medicine and Respiratory Care, \\ Hospital Bethanien Solingen, 42699 Solingen, Germany; lars.hagmeyer@klinik-bethanien.de \\ 8 Institute of Pathology, University Hospital of Cologne, 50937 Cologne, Germany; \\ reinhard.buettner@uk-koeln.de \\ 9 Institute for Hematopathology Hamburg, 22547 Hamburg, Germany; mtiemann@hp-hamburg.de \\ 10 Department of Pathology, University Medicine Essen-Ruhrlandklinik, University Duisburg-Essen, \\ 45147 Essen, Germany; hans-ulrich.schildhaus@uk-essen.de \\ 11 Institute of Epidemiology and Medical Biometry, Ulm University, 89075 Ulm, Germany; \\ Rainer.muche@uni-ulm.de \\ 12 NPARU, University of Worcester, Worcester WR2 6AJ, UK; lewisr@doctors.org.uk \\ 13 Division of Pulmonology, Cantonal Hospital Winterthur, 8400 Winterthur, Switzerland \\ * Correspondence: maik.haentschel@med.uni-tuebingen.de
}

\begin{abstract}
The detection of molecular alterations is crucial for the individualized treatment of advanced non-small cell lung cancer (NSCLC). Missing targetable alterations may have a major impact on patient's progression free and overall survival. Although laboratory testing for molecular alterations has continued to improve; little is known about how biopsy technique affects the detection rate of different mutations. In the retrospective study detection rate of epidermal growth factor (EGFR) mutations in tissue extracted by bronchoscopic cryobiopsy (CB was significantly higher compared to other standard biopsy techniques. This prospective, randomized, multicenter, single blinded study
\end{abstract}


evaluates the accuracy of molecular genetic characterization of NSCLC for different cell sampling techniques. Key inclusion criteria are suspected lung cancer or the suspected relapse of known NSCLC that is bronchoscopically visible. Patients will be randomized, either to have a CB or a bronchoscopic forceps biopsy (FB). If indicated, a transbronchial needle aspiration (TBNA) of suspect lymph nodes will be performed. Blood liquid biopsy will be taken before tissue biopsy. The primary endpoint is the detection rate of molecular genetic alterations in NSCLC, using CB and FB. Secondary endpoints are differences in the combined detection of molecular genetic alterations between FB and CB, TBNA and liquid biopsy. This trial plans to recruit 540 patients, with 178 evaluable patients per study cohort. A histopathological and molecular genetic evaluation will be performed by the affiliated pathology departments of the national network for genomic medicine in lung cancer (nNGM), Germany. We will compare the diagnostic value of solid tumor tissue, lymph node cells and liquid biopsy for the molecular genetic characterization of NSCLC. This reflects a real world clinical setting, with potential direct impact on both treatment and survival.

Keywords: NSCLC; molecular genetic characterization; bronchoscopy; cryobiopsy; forceps biopsy; next generation sequencing

\section{Background}

Lung cancer is one of the most common cancers, with 230,000 new diagnoses per annum in the United States and 410,000 in Europe, with a prevalence of approximately 1.8 million patients worldwide [1-4]. Non-small cell lung cancer (NSCLC) accounts for $75-85 \%$ of all lung cancers [5]. Two thirds of these patients are diagnosed in non-curable stage III or IV, and are usually treated systemically [6-8]. During the last decade, the systemic treatment has developed from a monomorphic platinum-based chemotherapy to a broad spectrum of individually tailored therapeutic approaches, based on the molecular tumor characterization of each patient [9]. NSCLC characterization is aligned to the existing specific therapeutics, but there are now rapidly developing new treatment options [10]. Patients' individualized treatment becomes more effective, not only because of the broader therapeutic spectrum, but also with the increase of progression free and overall survival (in certain situations) [11-18]. In addition, side effect profiles are better for most targeted drugs compared to the earlier chemotherapy [12-14,19-21]. However, detection of a distinct mutation, aberration or translocation of the tumor cells and the evidence of a specific immunoreactivity, as determined by the expression of programmed death-receptor 1 (PD-1) and its ligand (PD-L1) on tumor cell surface (PD-L1) or patients' T-cells (PD-1), are crucial to predict therapeutic effectiveness. So, the detection of a targetable structure predicts therapeutic response and therefore opens up the therapeutic window that would otherwise stay closed.

As a consequence, precise and correct characterization of the molecular genetic profile in patients with non-curable advanced stage III and IV NSCLC is crucial for ensuring optimal treatment; missing any targetable alteration may result in suboptimal therapy and could even impair patients' overall outcome. Molecular genetic tumor characterization may also be of importance in earlier tumor stages.

Although tumor analytics are claimed to be refined and sensitized down to a single cell level, thus enabling facilitated tumor detection and characterization in the peripheral blood [22], the clinical relevance of this approach analyzing a huge number of cells is unclear. Furthermore, the detection of a single tumor cell type does not necessarily reflect the tumor, with its inherent heterogeneity, since NSCLC tumor heterogeneity has been known and characterized in various studies for a long time [23-34]. However, such considerations have rarely been addressed in therapeutically oriented studies. More stringent tumor tissue requirements as a basis for tumor characterization have, up to now, been only vaguely specified or not specified at all, even in large studies or international guidelines [10,35-37]. So, there is a definite need to optimize tissue analytics to provide representative 
tumor characterization; but there is also currently a lack of a 'gold standard' for evaluation of this approach [38]. Although large tumor specimens are generally preferred for mutation assays [36]; the required sample size has not been evaluated in the past.

Cryobiopsy ( $\mathrm{CB}$ ) has already been confirmed to be superior to forceps biopsy (FB) for histopathological evaluation of endobronchial malignancies in a prospective study [39]. A retrospective study [40] has confirmed that there is a significant increase in epidermal growth factor (EGFR) detection rate for $\mathrm{CB}$ compared to $\mathrm{FB}$, but $\mathrm{CB}$ and $\mathrm{FB}$ have not yet been compared in terms of molecular genetic tumor characterization. Therefore, we have designed the PROFILER study to compare both bronchoscopic tissue sampling techniques (CB and $\mathrm{FB}$ ), transbronchial needle aspiration (TBNA) and liquid biopsy for their diagnostic yield in NSCLC.

\section{Methods/Design}

\subsection{Trial Design}

The PROFILER study is a prospective, multicenter, randomized, single blinded trial in accordance with the German Medical Association Professional Code. It has been designed to evaluate the accuracy of molecular genetic characterization of NSCLC, with the primary aim being to detect the best biopsy technique for tumor cell profiling. Five university hospitals or lung cancer centers across Germany will participate in the study. The enrolment of 356 evaluable patients is planned (Figure 1) with 178 patients having either CB or FB. Based on the study protocol Version 2.9, this study is currently recruiting (the first subject being enrolled on 19 December 2018). The PROFILER study has been registered on www.clinicaltrials.gov; NCT03971175.

\subsection{Patient Selection}

Patients with primary diagnosis of suspected, centrally localized lung cancer, or patients with known NSCLC and suspected relapse after therapy, form the study population. Inclusion and exclusion criteria are shown in Table 1A,B.

\subsection{Study Objectives}

The primary objective is to assess differences in detection of molecular genetic alterations in NSCLC between FB and CB (Figure 2).

The secondary objectives assess differences in the detection of molecular genetic alterations in NSCLC between liquid biopsy, solid tumor tissue biopsy obtained by bronchoscopic techniques, cytological material obtained by TBNA, and to compare combined methods (tissue biopsy, TBNA and liquid biopsy) with single techniques, to evaluate differences between naïve and processed tumor tissue specimens (e.g., by microdissection), and finally, to assess differences in side effects (e.g., peri-interventional bleeding).

The exploratory objectives analyze tumor mutational burden with regard to solid tumor tissue by FB or CB and cytologic material by TBNA and liquid biopsy.

\subsection{Pre-Procedural Training and Standardization}

All centers are already expert in the use of both forceps and cryobiopsy. Due to the integration or affiliation to the national network for genomic medicine lung cancer in Germany (nNGM), all participating pathologists will use the same standard for evaluation.

\subsection{Procedural Protocol}

\subsubsection{Patient Enrollment}

The local investigators pre-screen any potential participant with pulmonary lesions which were suspicious of lung cancer, or known NSCLC with suspected relapse or progression, in accordance 
with the inclusion and exclusion criteria; after giving informed consent, patients are eligible for study entry. Bronchoscopy is undertaken according to local standards, and in accordance with the published guidelines [41,42]. If endobronchial tumor is visible and reachable, inclusion criterion 4 is fulfilled, and the patient can be included in the study. A study flow chart is shown in Figure 1.

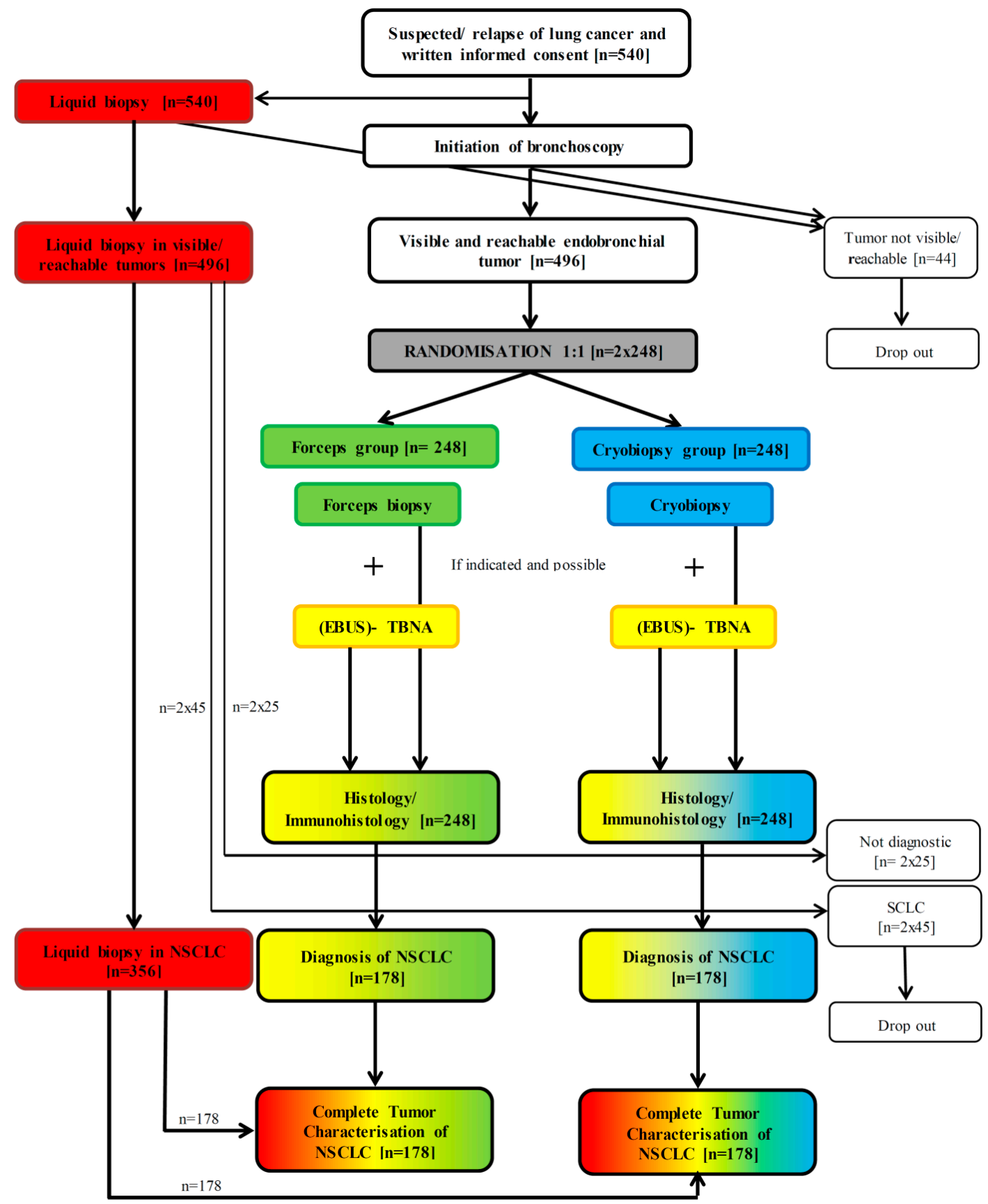

Figure 1. Flow chart of applied techniques and procedures. Assignment of colors: forceps biopsy-green; cryobiopsy—blue; (EBUS-) TBNA—yellow; liquid biopsy—red; (EBUS-) TBNA—endobronchial ultrasound guided transbronchial needle aspiration; NSCLC—non-small cell lung cancer; SCLC — small cell lung cancer. 
Table 1. (A) shows Inclusion criteria of the study; (B) shows Exclusion criteria of the study.

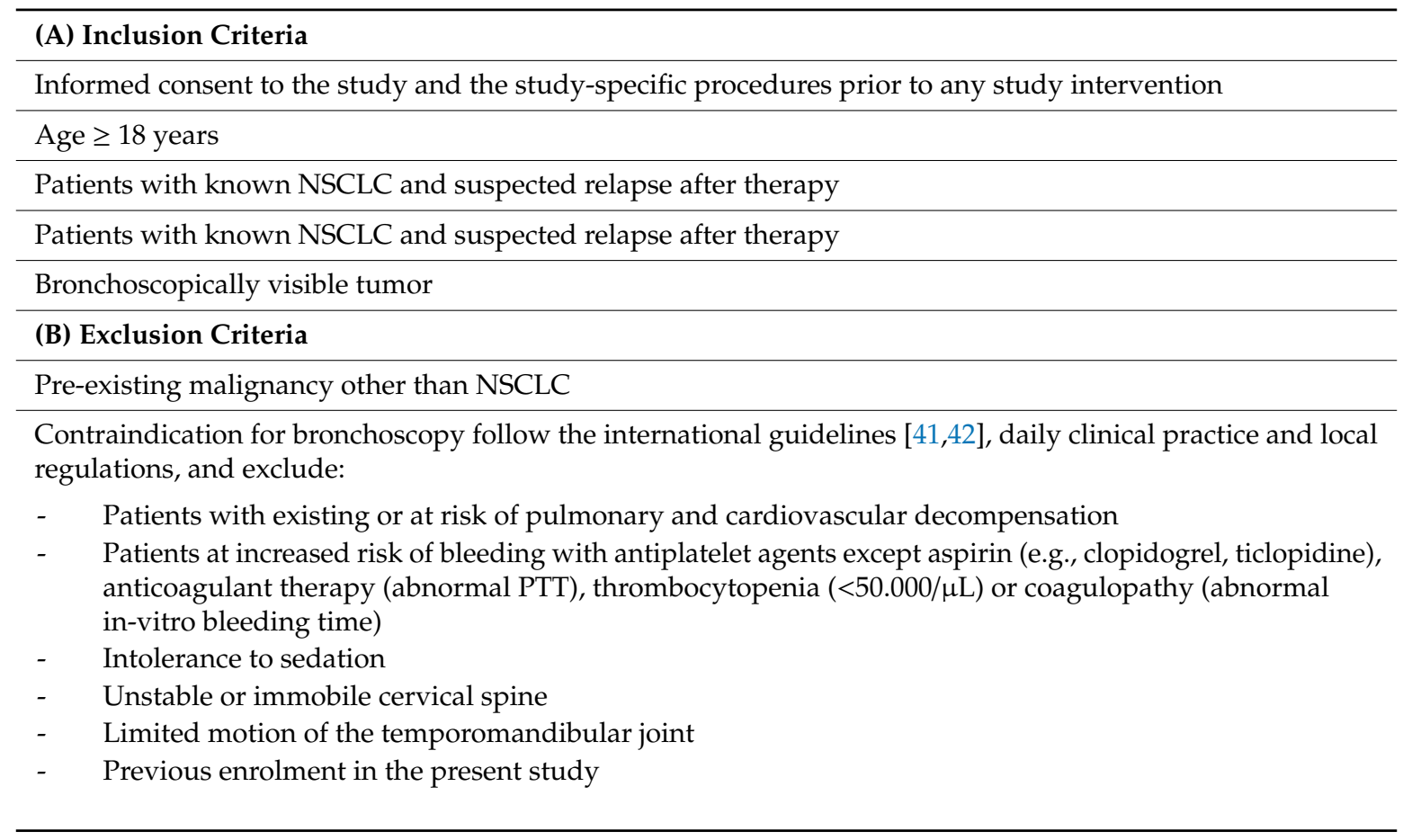

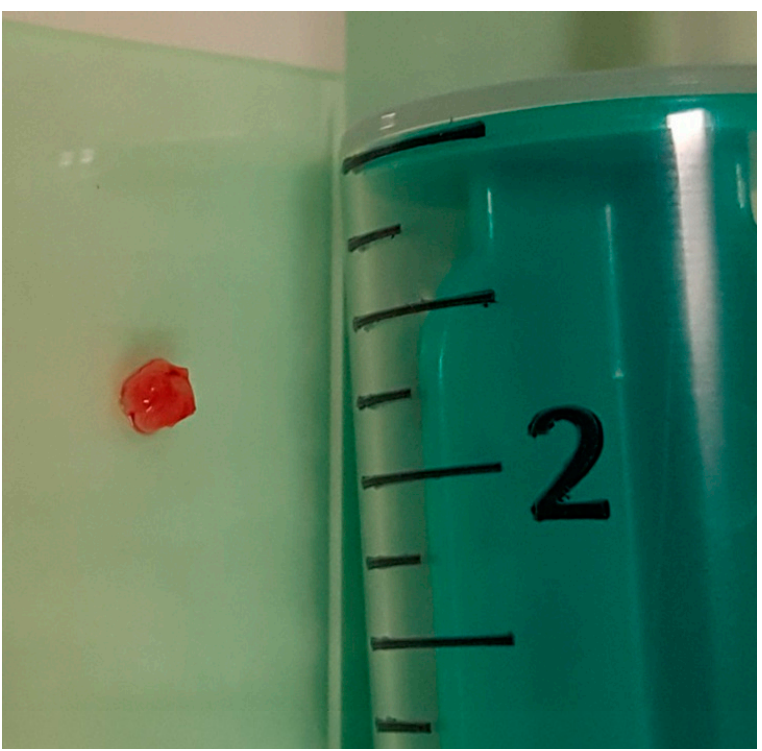

(A)

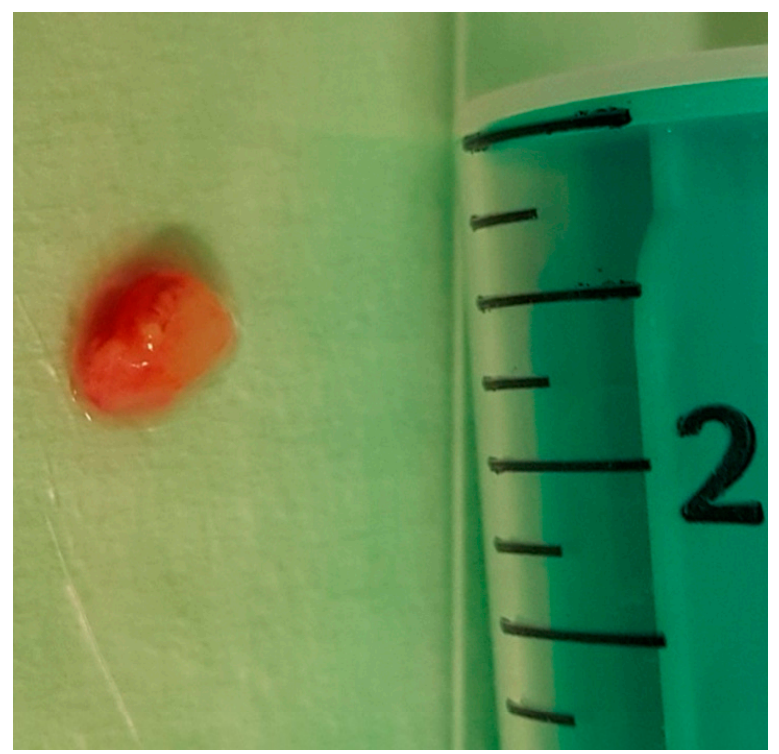

(B)

Figure 2. Examples of bronchoscopic forceps biopsy (A) and bronchoscopic cryobiopsy (B), as shown in two of the study patients.

\subsubsection{Randomization}

Patients are randomized to either FB or CB for tissue sampling by a stratified, balanced (1:1) block randomization, stratified by study site. The randomization will be prepared at the Institute of Epidemiology and Medical Biometry, University of Ulm. Sealed envelopes will be prepared for use in every study site, containing the randomized group. The opening of an envelope has to be documented in detail on the case report form (CRF). Liquid biopsy is performed in every patient included in the study, and TBNA is performed if indicated, depending on local investigators' decision, irrespective of randomization. 


\subsubsection{Liquid Biopsy Procedure}

Prior to any bronchoscopic intervention, blood is drawn for liquid biopsy analysis.

\subsubsection{Bronchoscopy}

Bronchoscopy is performed using either a flexible or rigid technique, depending on the operator's choice. In the case of flexible bronchoscopy, placement of an endotracheal tube is recommended in order to provide a secure airway. When rigid bronchoscopy is used, a tissue biopsy is carried out using a flexible bronchoscope inserted through the rigid tube. General anaesthesia will be used for rigid bronchoscopy, and deep sedation and local anaesthesia for intubation with a flexible tube. Patients will be monitored for oxygen saturation, ECG and repeated non-invasive blood pressure, according to the local standards of each center.

\subsubsection{Forceps and Cryobiopsy Procedure}

Depending on randomization, forceps or cryobiopsy are performed, in accordance with the guidelines and previous reports [39,41-44]. Forceps of a diameter between 1.8 and $2.6 \mathrm{~mm}$ are used for FB; cryoprobes of 1.9 or $2.4 \mathrm{~mm}$ (Erbe Elektromedizin $\mathrm{GmbH}$, Tübingen, Germany) are used for $\mathrm{CB}$. Freezing time for $\mathrm{CB}$ is dependent on the individual situation, morphology, localization, size and probe positioning, and is determined by the local investigator. A minimum of four biopsies will be taken.

\subsubsection{TBNA Procedure}

If indicated, TBNA is performed, preferentially under EBUS- guidance, to evaluate hilar and mediastinal lymph node metastasis. In some cases, TBNA may be done without EBUS guidance. EBUS equipment is not predefined by the study protocol; the procedure being performed according to the local standard and guidelines [45,46].

\subsection{Pathological Analysis}

\subsubsection{Baseline Pathological Evaluation}

The histological, immunohistological and immunohistochemical evaluation of extracted solid tissues by FB or $\mathrm{CB}$, and the cytological, immunocytological and immuncytochemical evaluation of TBNA extracted cytoblock or smear, are performed at the local pathological institute (including ALK, ROS 1 and PD-L1 expression level on tumor cells). Histological and immunohistological tissue evaluation, or cytological and immunocytological evaluation, assigns the tumor tissue to either NSCLC or small cell lung cancer (SCLC). Any cases of SCLC will be excluded from further analyses and classified as a 'drop out'. For any NSCLC, further molecular genetic evaluation will be undertaken, as described below.

Harmonization of the analytical processes is guaranteed in the study setting by the choice of the individual institutes of pathology, which are partners in the German national network of genomic medicine lung cancer (NGM lung cancer) [47], or which have participated in national collaborative ring trials. Additional collaborative ring trials for the analytical process will be performed for a selection of samples prior to the planned analytical process in this study.

\subsubsection{Molecular Genetic Evaluation}

Molecular genetic testing will be performed for solid bronchoscopically extracted material, for the cytological specimen extracted by TBNA (if applicable), and for the liquid biopsy samples. All currently targetable and non-targetable genetic aberrations, as suggested by the guidelines [10,35-37] (mutations, fusions, copy number variation $(\mathrm{CNV})$ ), as well as other important prognostic markers, are analyzed in accordance with the guidelines for standardized evaluation from the nNGM lung 
cancer consortium [48]. Targeted multigene mutation screening will be performed using different next generation sequencing techniques and platforms, depending on the participating site:

Tübingen: Amplicon library preparation will be done using the nNGM Panel 1.0 and 2.0. Semiconductor sequencing will be performed according to the manufacturers' manuals using the Ion AmpliSeq Library Kit v2.0, the Ion 510 and Ion 520 and Ion $530 \mathrm{Kit}-\mathrm{Chef}$ and the Ion 520 Chip Kit on the Ion GeneStudio S5 (Ion Reporter software) (Thermo Fisher Scientific, Waltham, MA, USA). Fusion and $\mathrm{CNV}$ detection will be undertaken with immunohistochemistry following fluorescent in situ hybridization, or with the Archer ${ }^{\circledR}$ FusionPlex Lung panel (Archer Analysis software, ArcherDX, Boulder, CO, USA).

Hamburg: The NEOselect assay (NEO New Oncology, Cologne, Germany) is used to detect single nucleotide mutations, copy number variations and fusions on the Illumina NextSeq system (Illumina, San Diego, CA, USA), according to the manufacturers' manual. In the case of very limited material, CNVs will be tested using PCR technologies such as cobas ${ }^{\circledR}$; fusion and CNV detection will be undertaken with immunohistochemistry.

Köln: The amplification of DNA will be performed using the customized GeneRead DNAseq custom Panel V2 with primers for the nNGM Panel 1.0 and 2.0 (Qiagen, Hilden, Germany), following the manufacturer's instructions. For library preparation, the Gene Read DNA Library I Core Kit and the Gene Read DNA I Amp Kit (Qiagen) will be used. After end-repair and adenylation, libraries were ligated to NEXTflex DNA Barcodes (Bio Scientific, Austin, TX, USA) and sequenced on the MiSeq (Illumina, San Diego, CA, USA) with a MiSeq reagent kit V2 (300 cycles) (Illumina), following the manufacturer's recommendations. Data will be exported as FASTQ files. Alignment, variant calling and annotation will be done using an in-house bioinformatic pipeline. A $5 \%$ cutoff for variant calls will be used, and results will only be interpreted if the coverage was $>200 \times$. The detection of gene fusions will either be done by a combination of immunohistochemistry and fluorescence in situ hybridization (FISH), or by using the Archer ${ }^{\circledR}$ FusionPlex Lung panel with the Archer Analysis software (ArcherDX, Boulder, CO, USA). CNVs will be analyzed by FISH.

Essen: The QIASeq Targeted DNA Panels (Qiagen, Hilden, Germany) nNGML1 and/or nNGML1.2 [48] will be run on an Illumina MiSeq or Illumina NextSeq platform, and the CLC Genomics Workbench versions 5.0.1, 12.0.3 or 20 will be used for data acquisition. Fusion and CNV detection will be carried out by immunohistochemistry, FISH, or by using Archer ${ }^{\circledR}$ FusionPlex CTL panel (ArcherDX, Boulder, CO, USA).

\subsection{Safety Data}

\subsubsection{Bleeding}

Bleeding is the most relevant side effect of any bronchoscopic biopsy and is categorized as shown in Table 2.

Table 2. Periinterventional bleeding.

\begin{tabular}{ll}
\hline Category & Intervention for Bleeding Control \\
\hline No & Self-limiting bleeding without need for any intervention for bleeding control \\
\hline Mild & $\begin{array}{l}\text { Self-limiting bleeding, manageable with suction alone and without the need for any } \\
\text { specific intervention }\end{array}$ \\
\hline Moderate & $\begin{array}{l}\text { Non self-limiting bleeding with need for suction plus additional intervention (alone or } \\
\text { in combination) including application of ice-cold saline or vasoconstrictors, or transient } \\
\text { balloon tamponade, leading to a termination of bleeding }\end{array}$ \\
\hline Severe & $\begin{array}{l}\text { Non self-limiting bleeding with need for suction, plus any additional intervention (alone or } \\
\text { in combination) and need for prolonged observation, stay in the hospital or intensive } \\
\text { care therapy }\end{array}$ \\
\hline Persistent/Fatal & Any persisting health impairment or death as a direct consequence of bleeding \\
\hline
\end{tabular}




\subsubsection{Other side Effects}

In addition to bleeding, hypoxia, cardiac arrhythmia, fever, infection and any other event attributable to the procedure will be evaluated.

\subsection{Statistical Methodology}

All analyses will be performed by the independent Institute of Epidemiology and Medical Biometry, Ulm University, after database lock and unblinding. A comprehensive statistical analysis plan (SAP) will be prepared prior to a first analysis of the study data.

\subsubsection{Sample Size Estimate}

Sample size calculation is based on the comparison of the detection rates for both techniques (FB and CB). Based on our earlier retrospective study, the cryobiopsy detection rate of EGFR was increased by approximately $50 \%$, from $14 \%$ to $21 \%$ [40]. As our primary endpoint combines various aberrations, including PD-L1-expression level, a rate of detectable alterations of around $40 \%$ could be expected. With an expected relative increase of almost $50 \%$ for aberrations, related to a frequency of $40 \%$, an absolute detection frequency of $55 \%$ was considered to be a conservative estimate.

The following assumptions were made for the sample size calculation: two-sided Chi-square test, type one error alpha $=0.05$, power $=0.80$. With a detection rate of $40 \%$ in the control FB group, and a conservative estimation of the detection rate of $55 \%$ in the experimental CB-group, and an assumption of equal number of patients in each group, 173 patients are required for each group, i.e., $2 \times 173=346$ patients in the whole trial.

Because of the short duration of observation in each patient, the rate of loss to follow up is very small. To allow a drop-out rate of up to 3\% 10 extra patients need to be recruited, resulting in a total sample size of 356 patients. As seen in Figure 1, the sample size for recruitment has to be increased, because NSCLC is likely to form $80 \%$ of all tumors; about 45 will be small cell lung cancer (SCLC) and about $10 \%$ ( 25 cases) would not be diagnostic in each cohort. Therefore, $2 \times 248$ patients will be required for randomisation. Although there is no current data, it can be assumed that in some cases an endobronchial tumor will not be visible. As a rough estimate, we assume that in $8 \%$ of the cases $(n=44)$, it will not be possible to take a biopsy from the central airways. This therefore determines that the total number of recruited suspected lung cancer patients is 540 .

Sample size calculation was performed by nQuery Advanced 8.1.

\subsubsection{Randomization}

The equality of study arms will be achieved by a stratified, balanced (1:1) block randomization. Randomization will be stratified according to study site. The randomization will be undertaken independently at the Institute of Epidemiology and Medical Biometry, University of Ulm, using the randomization software ROM. Sealed envelopes are prepared for use in each study site, which contain the randomized group.

\subsubsection{Blinding}

The study is single blinded, with the pathologists being blinded for the applied biopsy technique.

\subsubsection{Primary Endpoint Analysis}

The primary endpoint is the detection of at least one molecular genetic alteration in NSCLC. Confirmatory and exploratory data analyses are performed for this dichotomous primary endpoint as follows:

The difference in both groups based on the primary endpoint are evaluated using a Chi-square test (two sided at a significance level of 5\%). All further analyses of the primary endpoint will be performed in an exploratory fashion. All results from these analyses will be regarded as hypothesis-generating, 
and not as proof of efficacy. Univariate and multiple logistic regression models to adjust for strata (study site) and potential confounding variables will be performed.

\subsubsection{Secondary Endpoint Analysis}

The secondary, exploratory objectives and safety data are analysed by statistical methods for comparison of two unpaired groups, as appropriate for the characteristic of the variables, e.g., chi-square test for categorical and $t$-test/Mann-Whitney $U$ test for continuous variables. The assessment of the diagnostic value of liquid biopsy and TBNA, as both single techniques and in combination, will be undertaken by logistic regression analysis and ROC analysis. In order to investigate effects of subgroups and putative confounding factors, further analyses are performed, using generalized linear regression models as appropriate.

\subsection{Trial Oversight and Ethics Approval}

All procedures including FB, CB, TBNA and blood extraction for liquid biopsy are standardized routine and approved techniques using $\mathrm{CE}$ certified medical devices for diagnosis of lung cancer. The diagnostic workflow and its results are analyzed in this study setting, but they will not be altered at all, so all diagnostic procedures are performed as in routine clinical practice. This study protocol follows the German Medical Association Professional Code with institutional review board (IRB)-approval of the local IRB for each investigational site.

This clinical study is conducted in accordance with all appropriate laws and regulations, including, but not limited to, the Guideline for Good Clinical Practice (GCP), the Code of Federal Regulations (CFR), Directive 2001/20/EC, and the ethical principles of the Declaration of Helsinki and its amendments. Nothing in this document limits the authority of a physician to provide emergency medical care as appropriate.

This study was approved by the leading ethics committee at the University hospital of Tuebingen (644/2018BO1) between 29 August 2018 and 12 December 2018, and approved by local ethics committees at all participating study sites.

\section{Discussion}

As with many other malignancies, NSCLC cannot be considered as a single, monomorphic disease, but rather as a general term for a variety of lung malignancies with different causes, behaviors and prognoses which we are beginning to unravel. Existing and upcoming treatment options for many specified subtypes target identical molecular genetic changes/characteristics as the 'Achilles' heel' of the tumor. Such treatments have dramatically changed management and prognosis of patients over the last decade. However, to enable this increasingly individualized therapy, the exact characterization of each underlying tumor is crucial. Without detection of a specific aberration, e.g. a sensitizing EGFR mutation, the optimal targeted therapy would be ineffective [49-51]. On the other hand, missing a molecular genetic aberration, even in a subset of tumor cells, has a relevant and large impact on individual patients' treatment and prognosis.

Current diagnostic approaches are intended to address this central point by their steadily increasing sensitivity and specificity, ability to analyze the smallest tumor fragments and cytological material or cell free DNA on a single cell level. In addition, there is a desire for easier tumor material extraction, preferentially from the blood. Although this approach contradicts earlier guidelines for NSCLC analysis $[35,36]$, recent updates have focused on analytical techniques, displacing the role of tissue patterns to the background [10,37]. Tumor heterogeneity may be considered by such approaches, but the finding of any or several NSCLC clones does not guarantee that they represent the entire tumor.

Our previous observations have shown significant differences in EGFR detection between tumor tissue samples extracted by various techniques in a retrospective analysis [40]. This raises the question as to whether the diagnostic yield from different tissue or cytological sampling techniques differs, and if so, to what extent? The diagnostic value for each sampling technique alone has often been 
addressed [52-64], but, to our knowledge, differences in NSCLC diagnoses have only been analyzed between different techniques or biopsy sites $[65,66]$, but not in a prospective multicenter study that includes a large study cohort.

This PROFILER study approach uses the basic principles of tumor diagnostics, but takes into account that even the best available diagnostic tool may only be as good as the starting material to be analyzed [35,36]. In general, larger tumor specimens (e.g., resections) are preferred for mutation assays, because of a greater amount of material and a greater capacity to enrich the malignant content by dissection (as discussed in the molecular testing guideline by Lindeman et al.) [36] In the PROFILER study, we compare the complete tumor characterization between FB and CB standard bronchoscopic techniques as the primary endpoint. This concept goes far beyond existing comparisons [67-73], focusing on the adequacy and representative nature of all cell containing specimens that can be acquired for NSCLC diagnostics, since this has never been addressed in a prospective multicenter trial setting of this size. These results allow determination of which single technique or a combination of techniques best enables NSCLC tumor characterization.

Our study has some potential limitations that have to be addressed. The randomization to FB or CB could lead to an imbalance of the two cohorts, e.g., in terms of patient characteristics, tumor growth or stage, although the sample size should enable a good balance. The histological, cytological and molecular genetic evaluations are not undertaken by a single reference center; they are performed by different local pathologic institutes, using standardized, but sometimes different, analytic sets/kits. However, the multicenter approach for bronchoscopy and the pathological analyses enables the results to be more generalizable and represents a 'real world' setting.

Bleeding is the main side effect of bronchoscopic biopsy in visible endobronchial tumors. No difference has been shown in clinically relevant bleeding between $\mathrm{FB}$ and $\mathrm{CB}$ in prospective trials $[39,74]$.

With this study's focus on NSCLC diagnostics, we expect to obtain the essential information needed to optimize therapy, and anticipate that the findings will have an impact on both disease progression and survival in many NSCLC patients.

Author Contributions: M.H. and J.H. designed the study and wrote the study protocol. M.H., M.B., F.S. (Florian Schimmele), W.S., F.S. (Franz Stanzel), C.P., K.D., L.H., R.M. (Robert Mueller), B.A., J.H. performed the bronchoscopy at the participating centers. I.B., R.B., M.T., H.-U.S., H.B. and F.F. undertook the local pathology and molecular genetic evaluation. R.M. (Rainer Muche) prepared the randomization, supervised the statistical analysis process and performed the final statistical analysis. R.B., F.F. and L.Z. have given advice for the explorative research concept; F.E. performed data collection and supported the participating centers. R.A.L. advised and reviewed the writing process. All authors have read and agreed to the published version of the manuscript.

Funding: This investigator-initiated trial is supported by a grant from AstraZeneca. The funding source had no role in the design of this study and will not have any role during its execution, analysis, interpretation of the data, or its publication.

Acknowledgments: We thank all patients at the participating centers for their contribution to the study.

Conflicts of Interest: M.H., M.B. and J.H. have received personal fees from Erbe Elektromedizin GmbH for workshops. I.B. has received personal fees from Novartis, BMS and AstraZeneca, K.D. has received travel grants and lecture fees from ERBE and Olympus. No other authors have any conflicts of interests to declare.

Availability of Data and Materials: The datasets generated and/or analyzed during the current study are not publicly available, in accordance with the ethics committee's decision, but may be available from the corresponding author on reasonable request and with the ethics committee's consent.

\section{References}

1. Siegel, R.; Ma, J.; Zou, Z.; Jemal, A. Cancer statistics, 2014. CA A Cancer J. Clin. 2014, 64, 9-29. [CrossRef] [PubMed]

2. Cheng, T.Y.; Cramb, S.M.; Baade, P.D.; Youlden, D.R.; Nwogu, C.; Reid, M.E. The International Epidemiology of Lung Cancer: Latest Trends, Disparities, and Tumor Characteristics. J. Thorac. Oncol. Off. Publ. Int. Assoc. Study Lung Cancer 2016, 11, 1653-1671. [CrossRef] 
3. Ferlay, J.; Steliarova-Foucher, E.; Lortet-Tieulent, J.; Rosso, S.; Coebergh, J.W.; Comber, H.; Forman, D.; Bray, F. Cancer incidence and mortality patterns in Europe: Estimates for 40 countries in 2012. Eur. J. Cancer (Oxf. Engl. 1990) 2013, 49, 1374-1403. [CrossRef]

4. Miller, K.D.; Nogueira, L.; Mariotto, A.B.; Rowland, J.H.; Yabroff, K.R.; Alfano, C.M.; Jemal, A.; Kramer, J.L.; Siegel, R.L. Cancer treatment and survivorship statistics, 2019. CA A Cancer J. Clin. 2019. [CrossRef]

5. Meza, R.; Meernik, C.; Jeon, J.; Cote, M.L. Lung cancer incidence trends by gender, race and histology in the United States, 1973-2010. PLoS ONE 2015, 10, e0121323. [CrossRef]

6. Jemal, A.; Siegel, R.; Ward, E.; Hao, Y.; Xu, J.; Thun, M.J. Cancer statistics, 2009. CA A Cancer J. Clin. 2009, 59, 225-249. [CrossRef]

7. Morgensztern, D.; Ng, S.H.; Gao, F.; Govindan, R. Trends in stage distribution for patients with non-small cell lung cancer: A National Cancer Database survey. J. Thorac. Oncol. Off. Publ. Int. Assoc. Study Lung Cancer 2010, 5, 29-33. [CrossRef]

8. Goldstraw, P.; Chansky, K.; Crowley, J.; Rami-Porta, R.; Asamura, H.; Eberhardt, W.E.; Nicholson, A.G.; Groome, P.; Mitchell, A.; Bolejack, V. The IASLC Lung Cancer Staging Project: Proposals for Revision of the TNM Stage Groupings in the Forthcoming (Eighth) Edition of the TNM Classification for Lung Cancer. J. Thorac. Oncol. Off. Publ. Int. Assoc. Study Lung Cancer 2016, 11, 39-51. [CrossRef]

9. Aisner, D.L.; Marshall, C.B. Molecular pathology of non-small cell lung cancer: A practical guide. Am. J. Clin. Pathol. 2012, 138, 332-346. [CrossRef]

10. Lindeman, N.I.; Cagle, P.T.; Aisner, D.L.; Arcila, M.E.; Beasley, M.B.; Bernicker, E.H.; Colasacco, C.; Dacic, S.; Hirsch, F.R.; Kerr, K.; et al. Updated Molecular Testing Guideline for the Selection of Lung Cancer Patients for Treatment With Targeted Tyrosine Kinase Inhibitors: Guideline From the College of American Pathologists, the International Association for the Study of Lung Cancer, and the Association for Molecular Pathology. Arch. Pathol. Lab. Med. 2018, 142, 321-346. [CrossRef]

11. Yang, J.C.; Wu, Y.L.; Schuler, M.; Sebastian, M.; Popat, S.; Yamamoto, N.; Zhou, C.; Hu, C.P.; O’Byrne, K.; Feng, J.; et al. Afatinib versus cisplatin-based chemotherapy for EGFR mutation-positive lung adenocarcinoma (LUX-Lung 3 and LUX-Lung 6): Analysis of overall survival data from two randomised, phase 3 trials. Lancet Oncol. 2015, 16, 141-151. [CrossRef]

12. Zhou, C.; Wu, Y.L.; Chen, G.; Feng, J.; Liu, X.Q.; Wang, C.; Zhang, S.; Wang, J.; Zhou, S.; Ren, S.; et al. Erlotinib versus chemotherapy as first-line treatment for patients with advanced EGFR mutation-positive non-small-cell lung cancer (OPTIMAL, CTONG-0802): A multicentre, open-label, randomised, phase 3 study. Lancet Oncol. 2011, 12, 735-742. [CrossRef]

13. Rosell, R.; Carcereny, E.; Gervais, R.; Vergnenegre, A.; Massuti, B.; Felip, E.; Palmero, R.; Garcia-Gomez, R.; Pallares, C.; Sanchez, J.M.; et al. Erlotinib versus standard chemotherapy as first-line treatment for European patients with advanced EGFR mutation-positive non-small-cell lung cancer (EURTAC): A multicentre, open-label, randomised phase 3 trial. Lancet Oncol. 2012, 13, 239-246. [CrossRef]

14. Wu, Y.L.; Zhou, C.; Liam, C.K.; Wu, G.; Liu, X.; Zhong, Z.; Lu, S.; Cheng, Y.; Han, B.; Chen, L.; et al. First-line erlotinib versus gemcitabine/cisplatin in patients with advanced EGFR mutation-positive non-small-cell lung cancer: Analyses from the phase III, randomized, open-label, ENSURE study. Ann. Oncol. Off. J. Eur. Soc. Med Oncol. 2015, 26, 1883-1889. [CrossRef]

15. Fukuoka, M.; Wu, Y.L.; Thongprasert, S.; Sunpaweravong, P.; Leong, S.S.; Sriuranpong, V.; Chao, T.Y.; Nakagawa, K.; Chu, D.T.; Saijo, N.; et al. Biomarker analyses and final overall survival results from a phase III, randomized, open-label, first-line study of gefitinib versus carboplatin/paclitaxel in clinically selected patients with advanced non-small-cell lung cancer in Asia (IPASS). J. Clin. Oncol. Off. J. Am. Soc. Clin. Oncol. 2011, 29, 2866-2874. [CrossRef]

16. Sequist, L.V.; Yang, J.C.; Yamamoto, N.; O’Byrne, K.; Hirsh, V.; Mok, T.; Geater, S.L.; Orlov, S.; Tsai, C.M.; Boyer, M.; et al. Phase III study of afatinib or cisplatin plus pemetrexed in patients with metastatic lung adenocarcinoma with EGFR mutations. J. Clin. Oncol. Off. J. Am. Soc. Clin. Oncol. 2013, 31, 3327-3334. [CrossRef]

17. Yang, J.C.; Hirsh, V.; Schuler, M.; Yamamoto, N.; O’Byrne, K.J.; Mok, T.S.; Zazulina, V.; Shahidi, M.; Lungershausen, J.; Massey, D.; et al. Symptom control and quality of life in LUX-Lung 3: A phase III study of afatinib or cisplatin/pemetrexed in patients with advanced lung adenocarcinoma with EGFR mutations. J. Clin. Oncol. Off. J. Am. Soc. Clin. Oncol. 2013, 31, 3342-3350. [CrossRef] 
18. Mok, T.S.; Cheng, Y.; Zhou, X.; Lee, K.H.; Nakagawa, K.; Niho, S.; Lee, M.; Linke, R.; Rosell, R.; Corral, J.; et al. Improvement in Overall Survival in a Randomized Study That Compared Dacomitinib With Gefitinib in Patients With Advanced Non-Small-Cell Lung Cancer and EGFR-Activating Mutations. J. Clin. Oncol. Off. J. Am. Soc. Clin. Oncol. 2018, 36, 2244-2250. [CrossRef]

19. Zhou, C.; Wu, Y.L.; Chen, G.; Feng, J.; Liu, X.Q.; Wang, C.; Zhang, S.; Wang, J.; Zhou, S.; Ren, S.; et al. Final overall survival results from a randomised, phase III study of erlotinib versus chemotherapy as first-line treatment of EGFR mutation-positive advanced non-small-cell lung cancer (OPTIMAL, CTONG-0802). Ann. Oncol. Off. J. Eur. Soc. Med Oncol. 2015, 26, 1877-1883. [CrossRef] [PubMed]

20. Mok, T.S.; Wu, Y.L.; Thongprasert, S.; Yang, C.H.; Chu, D.T.; Saijo, N.; Sunpaweravong, P.; Han, B.; Margono, B.; Ichinose, Y.; et al. Gefitinib or carboplatin-paclitaxel in pulmonary adenocarcinoma. N. Engl. J. Med. 2009, 361, 947-957. [CrossRef] [PubMed]

21. Maemondo, M.; Inoue, A.; Kobayashi, K.; Sugawara, S.; Oizumi, S.; Isobe, H.; Gemma, A.; Harada, M.; Yoshizawa, H.; Kinoshita, I.; et al. Gefitinib or chemotherapy for non-small-cell lung cancer with mutated EGFR. N. Engl. J. Med. 2010, 362, 2380-2388. [CrossRef]

22. Yoneda, K.; Imanishi, N.; Ichiki, Y.; Tanaka, F. A liquid biopsy in primary lung cancer. Surg. Today 2019, 49, 1-14. [CrossRef]

23. Castello, A.; Russo, C.; Grizzi, F.; Qehajaj, D.; Lopci, E. Prognostic Impact of Intratumoral Heterogeneity Based on Fractal Geometry Analysis in Operated NSCLC Patients. Mol. Imaging Biol. Mib Off. Publ. Acad. Mol. Imaging 2018. [CrossRef]

24. Chen, Z.Y.; Zhong, W.Z.; Zhang, X.C.; Su, J.; Yang, X.N.; Chen, Z.H.; Yang, J.J.; Zhou, Q.; Yan, H.H.; An, S.J.; et al. EGFR mutation heterogeneity and the mixed response to EGFR tyrosine kinase inhibitors of lung adenocarcinomas. Oncologist 2012, 17, 978-985. [CrossRef] [PubMed]

25. Guo, L.; Chen, Z.; Xu, C.; Zhang, X.; Yan, H.; Su, J.; Yang, J.; Xie, Z.; Guo, W.; Li, F.; et al. Intratumoral heterogeneity of EGFR-activating mutations in advanced NSCLC patients at the single-cell level. BMC Cancer 2019, 19, 369. [CrossRef] [PubMed]

26. Jamal-Hanjani, M.; Wilson, G.A.; McGranahan, N.; Birkbak, N.J.; Watkins, T.B.K.; Veeriah, S.; Shafi, S.; Johnson, D.H.; Mitter, R.; Rosenthal, R.; et al. Tracking the Evolution of Non-Small-Cell Lung Cancer. N. Engl. J. Med. 2017, 376, 2109-2121. [CrossRef]

27. Jia, Q.; Wu, W.; Wang, Y.; Alexander, P.B.; Sun, C.; Gong, Z.; Cheng, J.N.; Sun, H.; Guan, Y.; Xia, X.; et al. Local mutational diversity drives intratumoral immune heterogeneity in non-small cell lung cancer. Nat. Commun. 2018, 9, 5361. [CrossRef]

28. Kwon, D.; Koh, J.; Kim, S.; Go, H.; Kim, Y.A.; Keam, B.; Kim, T.M.; Kim, D.W.; Jeon, Y.K.; Chung, D.H. MET exon 14 skipping mutation in triple-negative pulmonary adenocarcinomas and pleomorphic carcinomas: An analysis of intratumoral MET status heterogeneity and clinicopathological characteristics. Lung Cancer (Amst. Neth.) 2017, 106, 131-137. [CrossRef]

29. Mansuet-Lupo, A.; Zouiti, F.; Alifano, M.; Tallet, A.; Charpentier, M.C.; Ducruit, V.; Devez, F.; Lemaitre, F.; Laurent-Puig, P.; Damotte, D.; et al. Intratumoral distribution of EGFR mutations and copy number in metastatic lung cancer, what impact on the initial molecular diagnosis? J. Transl. Med. 2014, 12, 131. [CrossRef]

30. Nakamura, S.; Hayashi, K.; Imaoka, Y.; Kitamura, Y.; Akazawa, Y.; Tabata, K.; Groen, R.; Tsuchiya, T.; Yamasaki, N.; Nagayasu, T.; et al. Intratumoral heterogeneity of programmed cell death ligand-1 expression is common in lung cancer. PLoS ONE 2017, 12, e0186192. [CrossRef]

31. Remon, J.; Majem, M. EGFR mutation heterogeneity and mixed response to EGFR tyrosine kinase inhibitors of non small cell lung cancer: A clue to overcoming resistance. Transl. Lung Cancer Res. 2013, 2, 445-448. [CrossRef]

32. Soucheray, M.; Capelletti, M.; Pulido, I.; Kuang, Y.; Paweletz, C.P.; Becker, J.H.; Kikuchi, E.; Xu, C.; Patel, T.B.; Al-Shahrour, F; et al. Intratumoral Heterogeneity in EGFR-Mutant NSCLC Results in Divergent Resistance Mechanisms in Response to EGFR Tyrosine Kinase Inhibition. Cancer Res. 2015, 75, 4372-4383. [CrossRef]

33. Taniguchi, K.; Okami, J.; Kodama, K.; Higashiyama, M.; Kato, K. Intratumor heterogeneity of epidermal growth factor receptor mutations in lung cancer and its correlation to the response to gefitinib. Cancer Sci. 2008, 99, 929-935. [CrossRef] 
34. Zhang, L.L.; Kan, M.; Zhang, M.M.; Yu, S.S.; Xie, H.J.; Gu, Z.H.; Wang, H.N.; Zhao, S.X.; Zhou, G.B.; Song, H.D.; et al. Multiregion sequencing reveals the intratumor heterogeneity of driver mutations in TP53-driven non-small cell lung cancer. Int. J. Cancer 2017, 140, 103-108. [CrossRef]

35. Leighl, N.B.; Rekhtman, N.; Biermann, W.A.; Huang, J.; Mino-Kenudson, M.; Ramalingam, S.S.; West, H.; Whitlock, S.; Somerfield, M.R. Molecular testing for selection of patients with lung cancer for epidermal growth factor receptor and anaplastic lymphoma kinase tyrosine kinase inhibitors: American Society of Clinical Oncology endorsement of the College of American Pathologists/International Association for the study of lung cancer/association for molecular pathology guideline. J. Clin. Oncol. Off. J. Am. Soc. Clin. Oncol. 2014, 32, 3673-3679. [CrossRef]

36. Lindeman, N.I.; Cagle, P.T.; Beasley, M.B.; Chitale, D.A.; Dacic, S.; Giaccone, G.; Jenkins, R.B.; Kwiatkowski, D.J.; Saldivar, J.S.; Squire, J.; et al. Molecular testing guideline for selection of lung cancer patients for EGFR and ALK tyrosine kinase inhibitors: Guideline from the College of American Pathologists, International Association for the Study of Lung Cancer, and Association for Molecular Pathology. J. Thorac. Oncol. Off. Publ. Int. Assoc. Study Lung Cancer 2013, 8, 823-859. [CrossRef]

37. Kalemkerian, G.P.; Narula, N.; Kennedy, E.B.; Biermann, W.A.; Donington, J.; Leighl, N.B.; Lew, M.; Pantelas, J.; Ramalingam, S.S.; Reck, M.; et al. Molecular Testing Guideline for the Selection of Patients With Lung Cancer for Treatment With Targeted Tyrosine Kinase Inhibitors: American Society of Clinical Oncology Endorsement of the College of American Pathologists/International Association for the Study of Lung Cancer/Association for Molecular Pathology Clinical Practice Guideline Update. J. Clin. Oncol. Off. J. Am. Soc. Clin. Oncol. 2018, 36, 911-919. [CrossRef]

38. Liu, Y.; Dong, Z.; Jiang, T.; Hou, L.; Wu, F.; Gao, G.; He, Y.; Zhao, J.; Li, X.; Zhao, C.; et al. Heterogeneity of PD-L1 Expression Among the Different Histological Components and Metastatic Lymph Nodes in Patients With Resected Lung Adenosquamous Carcinoma. Clin. Lung Cancer 2018, 19, e421-e430. [CrossRef]

39. Hetzel, J.; Eberhardt, R.; Herth, F.J.; Petermann, C.; Reichle, G.; Freitag, L.; Dobbertin, I.; Franke, K.J.; Stanzel, F.; Beyer, T.; et al. Cryobiopsy increases the diagnostic yield of endobronchial biopsy: A multicentre trial. Eur. Respir. J. 2012, 39, 685-690. [CrossRef] [PubMed]

40. Haentschel, M.; Boeckeler, M.; Ehab, A.; Wagner, R.; Spengler, W.; Steger, V.; Boesmueller, H.; Horger, M.; Lewis, R.A.; Fend, F.; et al. Cryobiopsy increases the EGFR detection rate in non-small cell lung cancer. Lung Cancer (Amst. Neth.) 2020, 141, 56-63. [CrossRef] [PubMed]

41. Du Rand, I.A.; Barber, P.V.; Goldring, J.; Lewis, R.A.; Mandal, S.; Munavvar, M.; Rintoul, R.C.; Shah, P.L.; Singh, S.; Slade, M.G.; et al. British Thoracic Society guideline for advanced diagnostic and therapeutic flexible bronchoscopy in adults. Thorax 2011, 66 (Suppl. 3), iii1-iii21. [CrossRef]

42. Du Rand, I.A.; Blaikley, J.; Booton, R.; Chaudhuri, N.; Gupta, V.; Khalid, S.; Mandal, S.; Martin, J.; Mills, J.; Navani, N.; et al. British Thoracic Society guideline for diagnostic flexible bronchoscopy in adults: Accredited by NICE. Thorax 2013, 68 (Suppl. 1), i1-i44. [CrossRef] [PubMed]

43. Hetzel, J.; Hetzel, M.; Hasel, C.; Moeller, P.; Babiak, A. Old meets modern: The use of traditional cryoprobes in the age of molecular biology. Respir. Int. Rev. Thorac. Dis. 2008, 76, 193-197. [CrossRef] [PubMed]

44. Colella, S.; Haentschel, M.; Shah, P.; Poletti, V.; Hetzel, J. Transbronchial Lung Cryobiopsy in Interstitial Lung Diseases: Best Practice. Respir. Int. Rev. Thorac. Dis. 2018, 95, 383-391. [CrossRef]

45. Wahidi, M.M.; Herth, F.; Yasufuku, K.; Shepherd, R.W.; Yarmus, L.; Chawla, M.; Lamb, C.; Casey, K.R.; Patel, S.; Silvestri, G.A.; et al. Technical Aspects of Endobronchial Ultrasound-Guided Transbronchial Needle Aspiration: CHEST Guideline and Expert Panel Report. Chest 2016, 149, 816-835. [CrossRef]

46. van der Heijden, E.H.; Casal, R.F.; Trisolini, R.; Steinfort, D.P.; Hwangbo, B.; Nakajima, T.; Guldhammer-Skov, B.; Rossi, G.; Ferretti, M.; Herth, F.F.; et al. Guideline for the acquisition and preparation of conventional and endobronchial ultrasound-guided transbronchial needle aspiration specimens for the diagnosis and molecular testing of patients with known or suspected lung cancer. Respir. Int. Rev. Thorac. Dis. 2014, 88, 500-517. [CrossRef]

47. Buttner, R.; Wolf, J.; Kron, A. [The national Network Genomic Medicine (nNGM): Model for innovative diagnostics and therapy of lung cancer within a public healthcare system]. Der Pathol. 2019, 40, 276-280. [CrossRef]

48. National Network Genomic Medicine (nNGM). Centralized Testing-Decentral Treatment. Available online: https://www.nngm.de/en/ (accessed on 25 June 2020). 
49. Lynch, T.J.; Bell, D.W.; Sordella, R.; Gurubhagavatula, S.; Okimoto, R.A.; Brannigan, B.W.; Harris, P.L.; Haserlat, S.M.; Supko, J.G.; Haluska, F.G.; et al. Activating mutations in the epidermal growth factor receptor underlying responsiveness of non-small-cell lung cancer to gefitinib. N. Engl. J. Med. 2004, 350, 2129-2139. [CrossRef]

50. Paez, J.G.; Janne, P.A.; Lee, J.C.; Tracy, S.; Greulich, H.; Gabriel, S.; Herman, P.; Kaye, F.J.; Lindeman, N.; Boggon, T.J.; et al. EGFR mutations in lung cancer: Correlation with clinical response to gefitinib therapy. Science (N. Y.) 2004, 304, 1497-1500. [CrossRef]

51. Kobayashi, T.; Koizumi, T.; Agatsuma, T.; Yasuo, M.; Tsushima, K.; Kubo, K.; Eda, S.; Kuraishi, H.; Koyama, S.; Hachiya, T.; et al. A phase II trial of erlotinib in patients with EGFR wild-type advanced non-small-cell lung cancer. Cancer Chemother. Pharmacol. 2012, 69, 1241-1246. [CrossRef]

52. Tsunoda, A.; Morikawa, K.; Inoue, T.; Miyazawa, T.; Hoshikawa, M.; Takagi, M.; Mineshita, M. A prospective observational study to assess PD-L1 expression in small biopsy samples for non-small-cell lung cancer. BMC Cancer 2019, 19, 546. [CrossRef]

53. Naito, J.; Toyoda, T.; Nakajima, T.; Fujiwara, T.; Iwasawa, S.; Suzuki, H.; Takiguchi, Y.; Yoshino, I. A Repeated Biopsy by EBUS-TBNA Contributed to the Selection of an Appropriate Therapeutic Regimen for a Lung Cancer Patient. J. Bronchol. Interv. Pulmonol. 2019, 26, 129-131. [CrossRef]

54. Wisniewski, P.; Glogowski, M.; Olszewski, W. Assessment of diagnostic value of cytological examination in lung carcinoma in own material obtained by EBUS and EUS methods. Pol. J. Pathol. Off. J. Pol. Soc. Pathol. 2018, 69, 278-284. [CrossRef] [PubMed]

55. Raad, S.; Hanna, N.; Jalal, S.; Bendaly, E.; Zhang, C.; Nuguru, S.; Oueini, H.; Diab, K. Endobronchial Ultrasound-Guided Transbronchial Needle Aspiration Use for Subclassification and Genotyping of Lung Non-Small-Cell Carcinoma. South. Med. J. 2018, 111, 484-488. [CrossRef]

56. Goag, E.K.; Lee, J.M.; Chung, K.S.; Kim, S.Y.; Leem, A.Y.; Song, J.H.; Jung, J.Y.; Park, M.S.; Chang, Y.S.; Kim, Y.S.; et al. Usefulness of Bronchoscopic Rebiopsy of Non-Small Cell Lung Cancer with Acquired Resistance to Epidermal Growth Factor Receptor-Tyrosine Kinase Inhibitor. J. Cancer 2018, 9, 1113-1120. [CrossRef] [PubMed]

57. Stoy, S.P.; Segal, J.P.; Mueller, J.; Furtado, L.V.; Vokes, E.E.; Patel, J.D.; Murgu, S. Feasibility of Endobronchial Ultrasound-guided Transbronchial Needle Aspiration Cytology Specimens for Next Generation Sequencing in Non-small-cell Lung Cancer. Clin. Lung Cancer 2018, 19, 230-238.e232. [CrossRef]

58. Bonifazi, M.; Tramacere, I.; Zuccatosta, L.; Mei, F.; Sediari, M.; Paonessa, M.C.; Gasparini, S. Conventional versus Ultrasound-Guided Transbronchial Needle Aspiration for the Diagnosis of Hilar/Mediastinal Lymph Adenopathies: A Randomized Controlled Trial. Respir. Int. Rev. Thorac. Dis. 2017, 94, 216-223. [CrossRef]

59. Kirita, K.; Izumo, T.; Matsumoto, Y.; Hiraishi, Y.; Tsuchida, T. Bronchoscopic Re-biopsy for Mutational Analysis of Non-small Cell Lung Cancer. Lung 2016, 194, 371-378. [CrossRef]

60. Izumo, T.; Matsumoto, Y.; Chavez, C.; Tsuchida, T. Re-biopsy by endobronchial ultrasound procedures for mutation analysis of non-small cell lung cancer after EGFR tyrosine kinase inhibitor treatment. BMC Pulm. Med. 2016, 16, 106. [CrossRef]

61. Rooper, L.M.; Nikolskaia, O.; Carter, J.; Ning, Y.; Lin, M.T.; Maleki, Z. A single EBUS-TBNA procedure can support a large panel of immunohistochemical stains, specific diagnostic subtyping, and multiple gene analyses in the majority of non-small cell lung cancer cases. Hum. Pathol. 2016, 51, 139-145. [CrossRef]

62. Casadio, C.; Guarize, J.; Donghi, S.; Di Tonno, C.; Fumagalli, C.; Vacirca, D.; Dell’Orto, P.; De Marinis, F.; Spaggiari, L.; Viale, G.; et al. Molecular Testing for Targeted Therapy in Advanced Non-Small Cell Lung Cancer: Suitability of Endobronchial Ultrasound Transbronchial Needle Aspiration. Am. J. Clin. Pathol. 2015, 144, 629-634. [CrossRef]

63. Oki, M.; Saka, H.; Ando, M.; Kitagawa, C.; Kogure, Y.; Seki, Y. Endoscopic ultrasound-guided fine needle aspiration and endobronchial ultrasound-guided transbronchial needle aspiration: Are two better than one in mediastinal staging of non-small cell lung cancer? J. Thorac. Cardiovasc. Surg. 2014, 148, 1169-1177. [CrossRef]

64. Navani, N.; Brown, J.M.; Nankivell, M.; Woolhouse, I.; Harrison, R.N.; Jeebun, V.; Munavvar, M.; Ng, B.J.; Rassl, D.M.; Falzon, M.; et al. Suitability of endobronchial ultrasound-guided transbronchial needle aspiration specimens for subtyping and genotyping of non-small cell lung cancer: A multicenter study of 774 patients. Am. J. Respir. Crit. Care Med. 2012, 185, 1316-1322. [CrossRef] 
65. Schmid-Bindert, G.; Wang, Y.; Jiang, H.; Sun, H.; Henzler, T.; Wang, H.; Pilz, L.R.; Ren, S.; Zhou, C. EBUS-TBNA provides highest RNA yield for multiple biomarker testing from routinely obtained small biopsies in non-small cell lung cancer patients-A comparative study of three different minimal invasive sampling methods. PLoS ONE 2013, 8, e77948. [CrossRef]

66. Navani, N.; Nankivell, M.; Lawrence, D.R.; Lock, S.; Makker, H.; Baldwin, D.R.; Stephens, R.J.; Parmar, M.K.; Spiro, S.G.; Morris, S.; et al. Lung cancer diagnosis and staging with endobronchial ultrasound-guided transbronchial needle aspiration compared with conventional approaches: An open-label, pragmatic, randomised controlled trial. Lancet. Respir. Med. 2015, 3, 282-289. [CrossRef]

67. Cheng, Y.; Wang, Y.; Zhao, J.; Liu, Y.; Gao, H.; Ma, K.; Zhang, S.; Xin, H.; Liu, J.; Han, C.; et al. Real-world EGFR testing in patients with stage IIIB/IV non-small-cell lung cancer in North China: A multicenter, non-interventional study. Thorac. Cancer 2018, 9, 1461-1469. [CrossRef]

68. Hong, M.H.; Kim, H.R.; Ahn, B.C.; Heo, S.J.; Kim, J.H.; Cho, B.C. Real-World Analysis of the Efficacy of Rebiopsy and EGFR Mutation Test of Tissue and Plasma Samples in Drug-Resistant Non-Small Cell Lung Cancer. Yonsei Med. J. 2019, 60, 525-534. [CrossRef] [PubMed]

69. Komiya, K.; Nakashima, C.; Nakamura, T.; Hirakawa, H.; Abe, T.; Ogusu, S.; Takahashi, K.; Takeda, Y.; Egashira, Y.; Kimura, S.; et al. Current Status and Problems of T790M Detection, a Molecular Biomarker of Acquired Resistance to EGFR Tyrosine Kinase Inhibitors, with Liquid Biopsy and Re-biopsy. Anticancer Res. 2018, 38, 3559-3566. [CrossRef]

70. Kim, T.O.; Oh, I.J.; Kho, B.G.; Park, H.Y.; Chang, J.S.; Park, C.K.; Shin, H.J.; Lim, J.H.; Kwon, Y.S.; Kim, Y.I.; et al. Feasibility of re-biopsy and EGFR mutation analysis in patients with non-small cell lung cancer. Thorac. Cancer 2018, 9, 856-864. [CrossRef]

71. Chougule, A.; Basak, S. Epidermal growth factor receptor T790M testing in progressed lung cancer: A review of sensitive methods for analysis of tissue and liquid biopsy samples. Indian J. Cancer 2017, 54, S45-S54. [CrossRef]

72. Zanwar, S.; Noronha, V.; Joshi, A.; Patil, V.M.; Chougule, A.; Kumar, R.; More, S.; Goud, S.; Janu, A.; Mahajan, A.; et al. Repeat biopsy in epidermal growth factor receptor mutation-positive nonsmall cell lung cancer: Feasibility, limitations, and clinical utility in Indian patients. Indian J. Cancer 2017, 54, 280-284. [CrossRef] [PubMed]

73. Clery, E.; Pisapia, P.; Feliciano, S.; Vigliar, E.; Marano, A.; De Luca, C.; Malapelle, U.; Troncone, G.; Bellevicine, $\mathrm{C}$. There is still a role for cytology in the 'liquid biopsy' era. A lesson from a TKI-treated patient showing adenocarcinoma to squamous cell carcinoma transition during disease progression. J. Clin. Pathol. 2017, 70, 798-802. [CrossRef] [PubMed]

74. Ehab, A.; Khairy El-Badrawy, M.; Abdelhamed Moawad, A.; El-Dosouky Abo-Shehata, M. Cryobiopsy versus forceps biopsy in endobronchial lesions, diagnostic yield and safety. Adv. Respir. Med. 2017, 85, 301-306. [CrossRef] [PubMed]

(C) 2020 by the authors. Licensee MDPI, Basel, Switzerland. This article is an open access article distributed under the terms and conditions of the Creative Commons Attribution (CC BY) license (http://creativecommons.org/licenses/by/4.0/). 